\title{
Increasing Wear-resistance of Connectings Rod Bushing Supporting Surfaces in Crank Mechanisms
}

\author{
Oteny Ya.N. \\ Kamishin technological institute (branch) the Volgograd \\ state technical university \\ Kamishin, Russia \\ end@kti.ru
}

\author{
Morozova E.V. ${ }^{1,2}$ \\ ${ }^{1}$ Kamishin technological institute (branch) the Volgograd \\ state technical university \\ Kamishin, Russia \\ ${ }^{2}$ Saint Petersburg Electrotechnical University "LETI" \\ Saint Petersburg, Russia \\ end@kti.ru
}

Kazak V.F.

Kamishin technological institute (branch) the Volgograd state technical university

Kamishin, Russia

end@kti.ru

\begin{abstract}
The article deals with the issues of improving the reliability and durability of connecting rod supporting surfaces in crank mechanisms and internal combustion engines. The disadvantages of the currently used connecting rods are considered. In the process of the crank mechanism operation, due to intensive wear of the connecting rod and crankshaft journal contacting surfaces, it is often necessary to replace the connecting rod support pads. In this case, it is necessary to disassemble and subsequently assemble the entire crank mechanism or engine. On the basis of calculations using known formulas of the elasticity theory, it is shown that the presence of a gap between the hole in the connecting rod and the crankpin of the crankshaft, with the established tolerances, leads to the fact that they contact only on a part of the arc of the circle. In order to reduce contact stresses between the connecting rod and crankpin of the crankshaft and increase the contact area, the possibility of using a collapsible connecting rod is considered in the article, which makes it possible to provide a practically zero clearance when assembling the crank mechanism on the basis of the fit method, in return for group selection of the connecting rod liners. This allows you to compensate for wear on the bearing surfaces of the connecting rod and crankshaft without additional disassembly of the entire mechanism.
\end{abstract}

Keywords—crank mechanism; connecting rod; wearresistance; crankshaft; bushing

\section{INTRODUCTION}

Crankshafts and connecting rods that convert the reciprocating motion of the pistons into a rotational motion of the crankshaft are one of the most common parts in internal combustion engines and piston compressors.

The complexity in the processing and assembly of these mechanisms is the requirement for a high accuracy connection of connecting rods with crankshaft journals. These requirements are quite difficult to fulfill.
To improve the performance of crank-connecting mechanisms throughout the world, intensive research on their improvement has been and continues to be carried out throughout the whole period. [1-9]

\section{STUDY OF THE PROBLEM}

The main feature is that the reasons for the imperfection of crank mechanisms are embedded in the design itself. And they, in essence, are almost inevitable.

The peculiarity of the crankshafts, for example, in internal combustion engines, is that they are integral, and the connecting rods must be compound in order to be able to install them when assembled on crankpins of the crankshaft.

When working, the connecting rods are subject to significant alternating loads and inertia forces, so they must have high strength, wear resistance, stiffness and minimum weight.

These requirements determine the design of connecting rods (Fig. 1), which consists of a large crank head 1 and a small piston head 3 connected by rod 2 . 

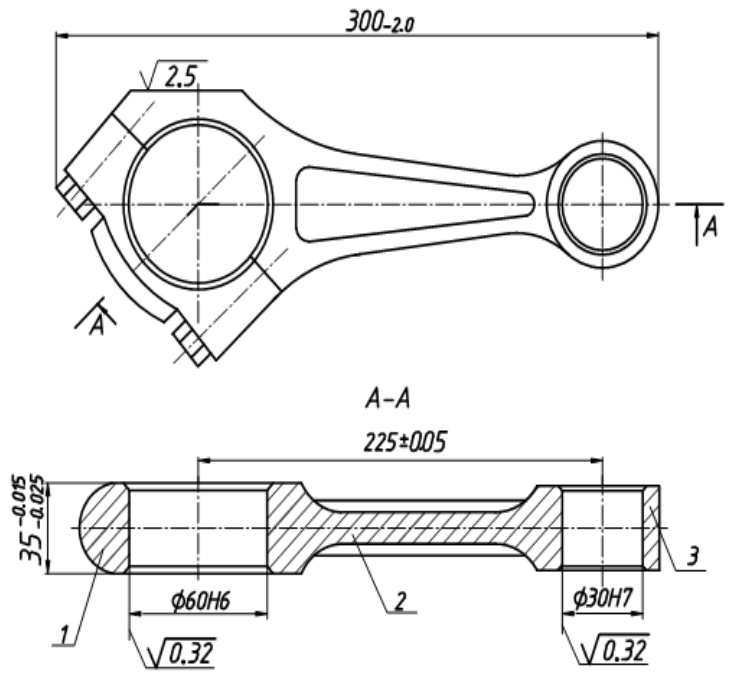

Fig. 1. Internal combustion engine connecting rod assembly.

In the holes of the crank heads of the connecting rods, to reduce the sliding friction, insert the liners with an antifriction coating. The small head of the connecting rod, as a rule, is not detachable, a bronze bimetal insert (steel - bronze) is pressed into its hole. Connecting-rod shank usually has a double-T section, which ensures a minimum mass of the connecting rod when transferring the necessary load to the piston.

In connecting rods, the inner surface of the hole adjacent to the collar area of the crankshaft is reinforced with thin-walled liners so that these surfaces can fit snugly to the corresponding crankpins. To do this, it is necessary to ensure a certain accuracy of diametrical dimensions and shapes, a roughness of the surface parameters of both heads and the accuracy of the surfaces arrangement.

The connecting accuracy of the connecting rods to the crankshaft journals is performed within the 6th or 7 th class of accuracy. In practice, in the manufacture of connecting rods and crankshafts, the accuracy of connecting dimensions is ensured by the method of group selection of bushings, which is an expensive method, especially for repair works.

The use of dismountable connecting rods reduces their manufacturability, increases the mass of connecting rods, which simultaneously leads to an increase in inertial loads. The bearing surfaces of the connecting rods and crankpin wear during operation intensively.

This causes the need for scheduled and unplanned repairs to replace the bushing of connecting rods. During repairs, it is not possible to apply the method of group selection of support inserts, so a fits method or a method of full interchangeability is used, which makes it necessary to very accurately produce them and, accordingly, increases the cost of repair work.

\section{RESULTS AND DISCUSSION}

At the same time, in the course of repair work, a simple and very accessible fit method can be used to improve the accuracy of fit between the bearing surfaces of the crankpins. This can be achieved by using a longitudinally-split connecting rod. rod.

Let us consider the features of this type of the connecting

In order to connect the fitment bore of the connecting rod to the crankpin and prevent their jamming, the fit between them must be carried out with guaranteed clearance and high accuracy.

The increase in the clearance reduces the contact area, which in turn leads to an increase in contact stresses and, accordingly, taking into account the high speeds of rotation of the crankshaft, leads to increased wear.

The use of a longitudinally-split connecting rod makes it possible to regulate the gap, both during the initial assembly and subsequent preventive maintenance without resorting to engine disassembly.

The solution to the issue of increasing the efficiency of the proposed new design of the longitudinally-split connecting rod can be based on a comparison of the values of contact stresses at the actual contact of the bearing surfaces of the connecting rod and the crankpin of the crankshaft used at the present time and a contact over the maximum possible contact surface (Fig. 2).

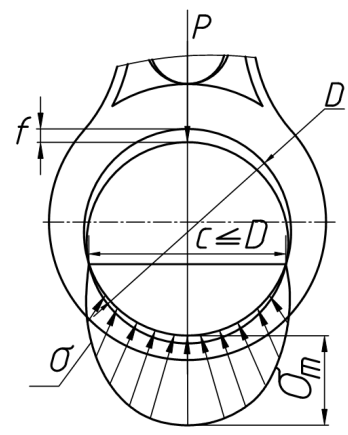

a)

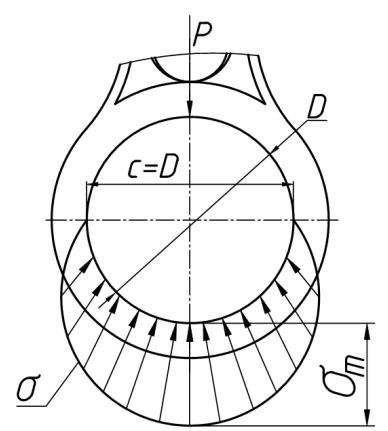

b)
Fig. 2. Schemes for contacting the crankpin and the inner seating surface of the connecting rod: a) actual contact; b) contact on the maximum possible contact surface.

When determining the contact stress between the crankpin surface and the hole with parallel axes, we use the solution to the Hertz problem for the case when the shaft contact occurs with the surface of the hole, between which there is a guaranteed clearance.

We assume that the elastic coefficients of the contacting surfaces of the connecting rod and the crankpin are equal.

According to this technique the calculation of contact width and maximum stresses at the center of contact, taking into account the gaps in the fit of bearing (fig. 2.a), can be calculated using equations:

The equation for calculating the width of the contact:

$$
c=1.08 \sqrt{\frac{p}{E} \cdot \frac{D_{1} \cdot D_{2}}{D_{1}-D_{2}}} .
$$


The equation for calculating the maximum stresses in the center of the contact zone:

$$
\sigma_{m}=0.59 \sqrt{p \cdot E \frac{D_{1}-D_{2}}{D_{1}-D_{2}}}
$$

Here $\mathrm{p}$ is the linear longitudinal load applied to the crankshaft neck (Fig. 2), equal to the ratio of the radial force to the length of the support neck; $D_{1}$ is the diameter of matching bore in the connecting rod; $\mathrm{D}_{2}$ is the diameter of the crankpin; $\mathrm{E}$ is the coefficient of elasticity of the materials to be contacted.

The difference between the diameter of the matching bore in the connecting rod and diameter of the crankpin forms a clearance that can be determined by the equation:

$$
f=D_{1}-D_{2}
$$

where $\mathrm{f}$ is the size of the clearance in the fit between the bushing of the bearing and the crankpin.

We derive the formula for $\mathrm{D}_{2}$ from (3), we obtain:

$$
D_{2}=D_{1}-f \text {. }
$$

If $D_{2}$ is replaced via (4) in (1) and (2), then the calculation of the thickness of the contact and the maximum stresses at the center of contact zone can be performed with the help of the equations:

$$
\begin{aligned}
c & =1.08 \sqrt{\frac{p}{E} \cdot \frac{D_{1}^{2}-\cdot D_{1} \cdot f}{f}} \\
\sigma_{m} & =0.59 \sqrt{p \cdot E \frac{f}{D_{1}^{2}-D_{1} \cdot f}} .
\end{aligned}
$$

If we represent the limiting case when the diameters of the crankpin and the hole of connecting rod coincide (which can be achieved by fitting the dimensions in the landing) (Fig. 2.b), then the stresses along the entire contact surface must be equalized, and the maximum stress will decrease.

If in (2) the diametrical clearance tends to zero, we find that the maximum stress at the center of contact also tends to zero, respectively, and the average stress will also tend to zero, and this contradicts the assumption that the sum of the stresses is equal to the applied load. It should be noted that it is not established when (1) and (2) can be used for what minimum clearance between the bearing surfaces of the crankpin and the hole in the connecting rod.

For the limiting case, when the surfaces of the connecting rod and supporting neck completely coincide, it is possible to apply the existing fundamental solution from the theory of elasticity [10], which is called the simple radial stress distribution.
The contact stresses distributed perpendiculars to the cylindrical surfaces are determined by the equation:

$$
\sigma_{r}=-\frac{2 p}{\pi} \cdot \frac{\cos \varphi}{r}, \sigma_{\varphi}=\tau_{\varphi}=0
$$

The longevity of the operation of the conjugation obviously depends more on the maximum voltage, and not on its average value.

The results of calculations performed by the authors in Fig. 3, 4, 5 .

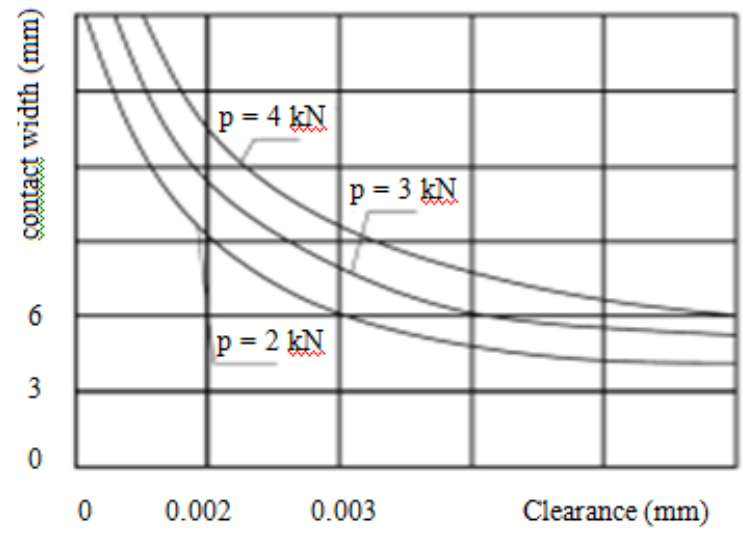

Fig. 3. The change of the contact width $c$ between the crankpin of the crankshaft and the bearing race, depending on the deformation and clearance $f$ in the joint for different values of the specific force $p$.

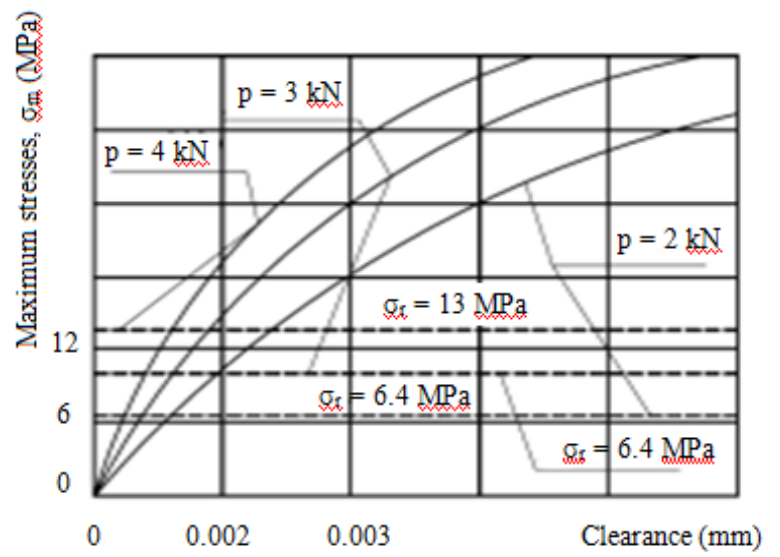

Fig. 4. Change in contact voltages between the crankpin and the connecting rod race acting on the crankshaft, depending on the deformation and clearance $f$ in the joint for different values of the specific force $p$. Horizontal straight lines correspond to contact stresses in the absence of a clearance. 


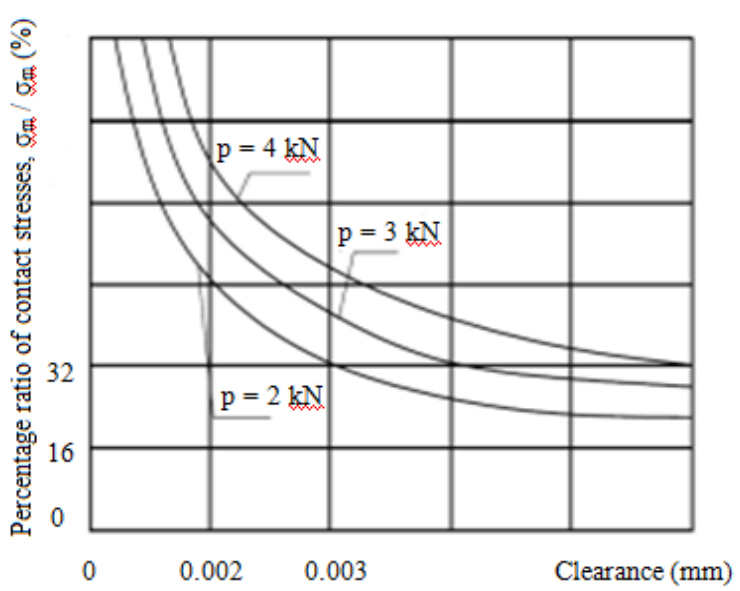

Fig. 5. Change of the percentage ratio of contact stresses in joints with clearance and without clearance between the crankpin and the connecting rod race, depending on the specific deformation force

It turned out that the actual contact width along the arc in the basic version between the crankpin and the hole in the connecting rod is much smaller than the diameter of the hole in the connecting rod, which is taken as the width of the contact in calculations according to the techniques given in the manuals and does not exceed $35 \%$ (Fig. 5). The width of the contact decreases in proportion to the increase in the clearance. At the same time, the maximum voltages in the contact increase proportionally (Fig. 4).

The most important conclusion is a sharp decrease in the maximum contact stresses with a decrease in the clearance between the bearing mounting surface in the connecting rod and the bearing surface of the crankpin. From the presented graph in Fig. 5 it is seen that with the increase of the clearance to $0.01 \mathrm{~mm}$, this difference is $16 \%$.

Fig. 6 shows the proposed design of the connecting rod assembly, which has a longitudinal section along the section AA.
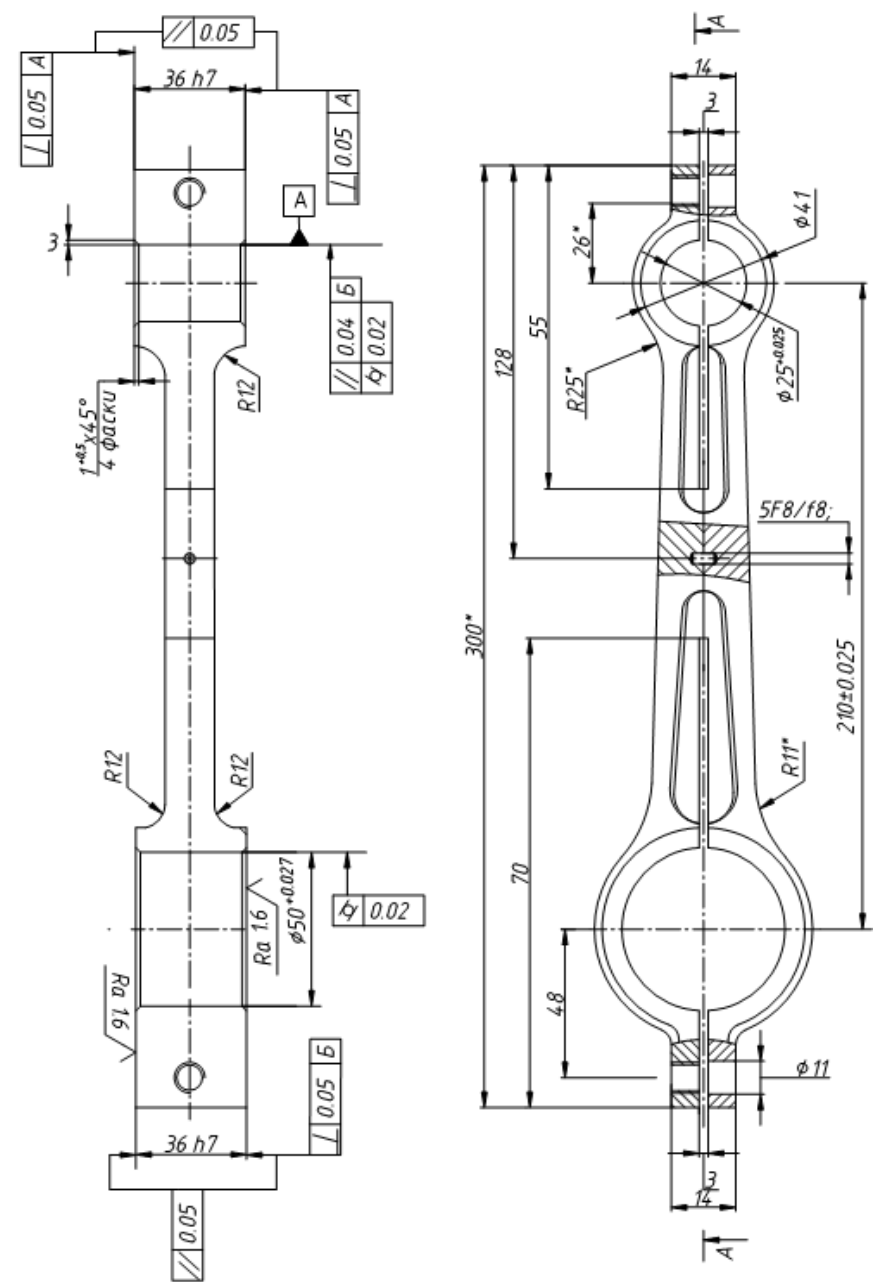

Fig. 6. The construction of the longitudinally-split connecting rod

Before installing the connecting rod into the working position during the assembly, first one inserts liners 5 on the pin and the support crankpin (Fig. 7) and then connects both halves of the connecting rod with the centering pin 7 . Then one must tighten screws 8 and 9 until they compensate the clearance between liners 5 and 6 .

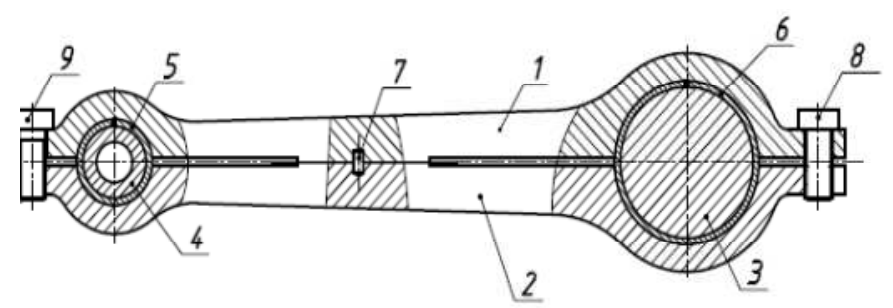

Fig. 7. Design of the longitudinally-split connecting rod with the crankshaft assembly: 1 is the upper part of the connecting rod; 2 is the lower part of the connecting rod, the 3 is the bearing crankpin, 4 is the piston pin; 5 is the bushing for the pin; 6 is bushing of the crankpin; 7 is the centering pin; 8,9 are adjusting screws.

The moment when the zero clearance is provided, can be determined by the torque, by turning the crankshaft manually using a torque wrench. 
It is necessary to proceed similarly after a certain engine operation period before scheduled maintenance. It is not necessary to completely disassemble the engine, but just remove the crankcase cover.

\section{CONCLUSION}

As a result of the studies presented in the article, it is shown that at present, despite the long period of use of the crank-and-rod mechanisms, especially in internal combustion engines, they have some principal drawbacks, mainly due to insufficient durability due to wear between the inserts support surfaces of connecting rods and bearing crankpins of a cranked shaft.

This leads to the need for periodic preventative maintenance. In this case it is necessary to disassemble and subsequently assemble the mechanism.

In order to eliminate these drawbacks, based on the calculations of the dependencies given in the theory of elasticity, it has been found possible to find an acceptable solution for reducing contact stresses between the surfaces of the connecting rods bearing journals and crankpins on the basis of the method of fitting the gaps between their rubbing surfaces, directly in the working mechanism without dismantling it.

\section{References}

[1] A.K. Bolotov, L.A. Loparev, Construction of cars. Moscow: Kolos, 2006.

[2] V.V. Dubina, N.P. Chikunov, Crank mechanism and gas distribution mechanism of the internal combustion engine. Saransk: Publisher Mord. University, 2003.

[3] P.F. Dunaev, OP Lelikov, Calculation of size tolerances. Moscow: Mechanical Engineering, 1992.

[4] A.P. Inshakov, A.M. Karpov, S.K. Slavkin, Practical work on the construction of cars. Saransk: Publisher Mord. University, 2003.

[5] V.I. Karagodin, M.N. Mitrokhin, Repair of cars and engines. Moscow: High School, 2001.

[6] G.M. Kutkov, Cars. Theory and technological properties. Moscow: Kolos, 2004.

[7] E.A. Shadrichev, Fundamentals of automotive technology and car repair, Moscow: Mechanical Engineering, 1976.

[8] D.N. Vyrubov, S.I. Efimov, N.A.Ivaschenko, Engines of internal combustion. Design and calculation of the strength of reciprocating and combined engines. Moscow: Mechanical engineering; 1984.

[9] E.L. Volovik, Handbook on the restoration of parts, Moscow: Kolos, 1981.

[10] I. Ya. Shtaerman, Contact problem of the theory of elasticity. Moscow: Gostekhizdat, 1949. 